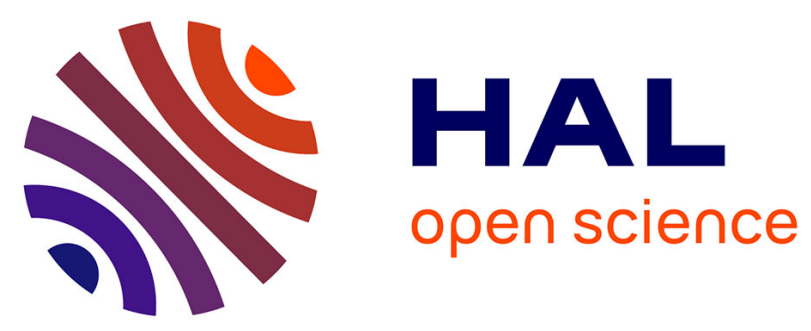

\title{
Micromechanical and microstructural investigation of steel corrosion layers of variable age developed under impressed current method, atmospheric or saline conditions
}

\author{
A Dehoux, Fatiha Bouchelaghem, Y Berthaud
}

\section{To cite this version:}

A Dehoux, Fatiha Bouchelaghem, Y Berthaud. Micromechanical and microstructural investigation of steel corrosion layers of variable age developed under impressed current method, atmospheric or saline conditions. Corrosion Science, 2015, 97, pp.49-61. 10.1016/j.corsci.2015.04.016 . hal-01161954

\author{
HAL Id: hal-01161954 \\ https://hal.sorbonne-universite.fr/hal-01161954
}

Submitted on 9 Jun 2015

HAL is a multi-disciplinary open access archive for the deposit and dissemination of scientific research documents, whether they are published or not. The documents may come from teaching and research institutions in France or abroad, or from public or private research centers.
L'archive ouverte pluridisciplinaire HAL, est destinée au dépôt et à la diffusion de documents scientifiques de niveau recherche, publiés ou non, émanant des établissements d'enseignement et de recherche français ou étrangers, des laboratoires publics ou privés. 


\title{
Micromechanical and microstructural investigation of steel corrosion layers of variable age developed under impressed current method, atmospheric or saline conditions
}

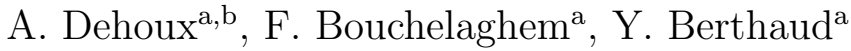 \\ ${ }^{a}$ UPMC Univ Paris 06, UMR 7190, Institut Jean Le Rond d'Alembert, F-75005 Paris, \\ France. \\ ${ }^{b}$ Andra - Agence Nationale pour la gestion des Déchets RadioActifs, 1-7 rue Jean \\ Monnet, 92298 Chatenay Malabry, France.
}

\begin{abstract}
In this paper, we have gathered the conclusions of an experimental campaign dedicated to the microstructural characterization and the determination of the local elastic properties of various natural and artificial corrosion product layers. The results of micro-indentation testing and Raman spectroscopy coupled with a semi-quantitative analysis have been presented for the whole set of investigated materials, from early-age (2 weeks) corrosion products to 660 years-old massive corroded samples. An interpretation of the local Young's modulus and hardness values has been proposed by relying on a Gaussian mixture model. The relation between the observed morphologies of the corrosion products layers, their composition and the distribution of elastic modulus and indentation hardness has finally been discussed.
\end{abstract}

Keywords: A. Steel reinforced concrete

B. Raman spectroscopy

C. Atmospheric corrosion

C. Rust

Email addresses: fatiha.bouchelaghem@upmc.fr (F. Bouchelaghem), 0033144 278707 (F. Bouchelaghem) 


\section{Introduction}

The long-term isolation of radioactive waste in deep repositories relies on a multi-barrier concept in order to guarantee that no significant environmental releases occur over a long period after disposal. The immobilized or compacted waste packages are sealed inside reinforced concrete canisters and surrounded with bentonite clay before being located deep underground in a stable rock structure. In this multi-barrier concept, the reinforced concrete canisters are aimed to contribute to the mechanical stability of the storage, as well as to limit the mass transfer between the waste and the biosphere [1]. Consequently, it seems essential to understand the hydro-mechanical behaviour of all the materials involved and the possibly evolving interfaces between the various materials appear as a key aspect in the assessment of their long term performance.

Owing to the lack of available data concerning the mechanical properties of iron oxides at the mesoscopic scale of corrosion layers, the presence of evolving corrosion product layers at the interface between the concrete and the rebar cannot be explicitly taken into account in multiphase or multiscale models. For such a reason, our project has been dedicated to the mechanical characterization of corrosion layers formed within carbonated reinforced concrete $[2,3]$. As our work is mainly concerned with natural corrosion layers developed over the long term, such corrosion products have been sampled from old constructions, whose steel is completely corroded $[4,5,6,7]$. However, in order to compare our findings with the data available in the 
published literature, which deal generally with artificially created corrosion, our study also encompasses corrosion samples developed in the laboratory under an imposed electric current (accelerated corrosion) [8, 9] or under a saline environment $[10,11,12,13]$.

The Dense Product Layer (DPL) of iron oxides that develop at the interface between the remaining reinforcement and the concrete presents a complex, highly heterogeneous structure. At the micrometer scale, different phases are encountered in varying proportions. A small porosity (around 10 $\%$ is also present, consisting mostly of cracks of finite extension approximately oriented along the initial rebar $[2,14,15,16,17]$. Depending on the kind of corrosion - natural or synthetized, the environmental conditions of corrosion and the age of the samples, the estimated modulus of the DPL at the mesoscopic scale is comprised between $0.1 \mathrm{GPa}$ and $200 \mathrm{GPa}[2,9,13,18]$. Apart from the heterogeneous microstructure, the great dispersion of the published data is also due to the identification procedure. The lowest values of Young's modulus, of the order of $0.1 \mathrm{GPa}$, are found in $[8,13,9,19,20]$, and may not be viewed as intrinsic values of the elasticity modulus. In those references, macroscopic experiments on composite samples comprising the concrete and the rebar corroded under impressed current, are numerically simulated in order to reproduce the time for cover-crack initiation. The latter approach requires the back-calculation of the elastic properties of corrosion layers using Finite Element computations based on an analogy with thermo-elasticity, the thermal expansion coefficient representing the expan- 
sion ratio of the corrosion products. Such an analogy has proved convenient to express some effects of the corrosion development on the damage of the cover concrete, and requires very low values of Young modulus for corrosion products as an input data in order to obtain realistic predictions. In other studies $[21,22,23]$, the mechanical properties have been measured on macroscopic samples of rust particles reduced to powder, using oedometer tests. The resulting moduli are comprised between 0.3 and $5 \mathrm{GPa}$, this may be explained by the fact that the initial structure of the corrosion products has been completely destroyed, the investigated samples behave consequently as granular materials instead of the initial layered structure with strong cohesion between the different corrosion layers. In [21], the exploitation of oedometer test results using Hertz theory of contacting spheres leads in contrast to very high values of elasticity modulus, comprised between 307 and 477 GPa. The latter values are close to Young's moduli measured by [24, 25] on mono or poly-crystals of magnetite. In recent studies, depth sensing nanoindentation $[18,26]$ or micro-indentation [3] have been employed in order to identify the local elasticity modulus and Vickers hardness of corrosion layers at the micrometer scale of the heterogeneous corrosion layers. The resulting values measured on natural $[18,3]$ or artificial [26] corrosion products are comprised between 51 and $158 \mathrm{GPa}$.

Owing to the great dispersion of the mechanical properties identified for iron oxides, and to their complex microstructure, it appears therefore necessary to study the porous DPL at the level of its components, with an aim 
to characterize the mechanical behaviour of corrosion layers at the mesoscopic scale in relation with typical microstructural features. In the continuity of a preceding work [3], Raman micro-spectrometry coupled with semi-quantitative interpretation using CorATmos software [4, 27], and depth sensing micro-indentation have been employed on a variety of corrosion samples. For all the investigated materials, the results of more than 440 microindentation points and 1500 Raman spectra are summarized and discussed in the present paper. Whenever possible, the indentation test results have been interpreted using a Gaussian mixture model [28] which allows differentiating between groups characterized by statistically distinguishable mechanical properties (hardness and local elasticity modulus). The interpretation of microstructural and micromechanical data has enabled us then to identify a number of representative constituents and microstructural arrangements for each sample depending on the kind of corrosion (natural or artificial) and its age, as well as average mechanical properties for each representative groups of constituents.

\section{Experimental}

\subsection{Materials}

The study has been conducted on different types of corrosion products, from early-age corrosion synthetized in the laboratory to on-site, massive corrosion layers sampled on ancient buildings.

Corrosion products of reinforcing bars embedded in a concrete building 
A specimen of reinforced concrete building, aged approximately 50 years, has been taken in the urban area of Paris (France), Figure 1(a). This specimen is composed of ordinary concrete and the remaining part of a corroded rebar, and presents the advantage of maturation under the atmospheric cycles of the Parisian region. This sample allows to investigate atmospheric corrosion in a contemporary concrete under known carbonation conditions. From the test with phenolphthalein displayed in Figure 1(a), we can notice that the upper surface of the mortar as well as a few localized areas around the corrosion layers are carbonated. However, the amount of corrosion products is limited (the maximum width of the corrosion layer is about $2 \mathrm{~mm}$ ) and is not sufficient to conduct a complete experimental investigation.

Atmospheric corrosion of ferrous archeological artefacts

For this reason, and also because we are investigating long-term corrosion, we have chosen to focus our study on ancient ferrous artefacts embedded in aerial and hydraulic unsaturated binders exposed to atmospheric conditions. Such corroded samples originate from the Palais des Papes in Avignon, France, and are aged about 660 years [3, 14, 16], Figure 1. Although the composition of the mortar surrounding the reinforcement and the steel employed differ from the materials employed in modern constructions, a thorough experimental study at several scales on such multisecular samples has enabled us to estimate the long-term elastic properties of steel corrosion [2]. These samples are completely corroded, and appear as a highly heterogeneous porous material, essentially composed of iron, oxygen, with crack-like 
pores. As illustrated in Figure 2 displaying X-ray tomography results obtained using a resolution of $7 \mu \mathrm{m}$, we observe a dark matrix crossed with clear marblings characterized by a higher proportion of steel. In the (x,y)and $(\mathrm{z}, \mathrm{x})$ - planes, we observe nearly parallel and very elongated pores in black, while in the (y,z)-plane no noticeable porosity can be detected. The porosity is essentially plane and of variable length (along z) but finite lateral extent (along y).

\section{Corrosion synthetized in the laboratory under impressed current method} Most of the mechanical studies encountered in the available literature concern corrosion layers synthesized under an imposed electrical current. Consequently, the micromechanical characterization procedure has also been extended to such artificial corrosion products, in view of comparison with existing data.

The parallelepiped samples, of dimensions $2 \times 3 \times 5 \mathrm{~cm}^{3}$, consist in a steel plate surrounded by mortar, Figure 1. The plates employed, of width 0.2 mm, are composed of non-alloy steel F12. The mortar is a cement CEM I 52.5. In order to maximize the pore volume and to facilitate the mass transfers responsible for carbonation, we have chosen a cement-to-water ratio of $C / E=0.6$, and a sand-to-cement ratio $S / C=3$. The normalized sand used (CEN, $0.08 / 2 \mathrm{~mm})$ is a natural siliceous sand [2]. The development of corrosion products is accelerated under an imposed electrical current, following a procedure similar to $[9,19]$. Sodium chloride $(\mathrm{NaCl})$, amounting to 3.5 wt. \% 
of the mixing water, is added. The samples are then partially immersed in a basic solution $(\mathrm{pH}=13)$, composed of $\mathrm{KOH}\left(4.65 \mathrm{~g} \mathrm{l}^{-1}\right)$ and $\mathrm{NaCl}\left(30 \mathrm{~g} \mathrm{l}^{-1}\right)$, and afterwards the acceleration of corrosion takes place under an imposed current of $100 \mu \mathrm{A} \mathrm{cm}^{2}$.

Corrosion in laboratory samples of reinforced concrete under saline environment

For comparison purposes, we have also tried to characterize the corrosion products developed in the laboratory within several macroscopic structures of ordinary reinforced concrete, of variable age, Figure 1. Samples corroded in the laboratory under a controlled saline environment [11], of age comprised between 3 and 25 years, have thus been characterized at the scale of the microstructure. The testing sample aged of 3 years has been extracted from a wall of $1100 \mathrm{~mm}$ width. After a curing period of 28 days in water at $293 \mathrm{~K}$, the sample has been dried at $323 \mathrm{~K}$ until reaching a constant mass, before being immersed in brine ( $35 \mathrm{~g} \mathrm{l}^{-1}$ of $\left.\mathrm{NaCl}\right)$. Afterwards, cycles of 7 days in brine have been alternated with 15 days of drying, we refer to [29] for a detailed description of the procedure. We did not observe any visible cracks on the surface of the sample. The 14 years old cylindrical sample aged 14 years has been stored in a conservation room under brine before being subjected to wetting/drying cycles The sample aged 25 years has been taken from a beam submitted to a three-point flexion test conducted until rupture $[10,12]$. The corroded beams have been exposed to a saline environment during 6 years, followed by cycles of wetting/drying during seven years [11]. 
Regarding the preparation procedure in view of micromechanical testing, all the samples were completely cast in epoxy resin at room temperature, cross-sectioned and polished to $3 \mu \mathrm{m}$ with ethanol, before being cleaned in an ultrasonic bath, rinsed with ethanol and dried.

2.2. Physico-chemical and mechanical characterization at the micrometer scale

\subsubsection{Raman microspectroscopy}

The identification of the elementary constituants has been conducted for all the samples using Raman and SEM EDS analysis (with a Stereoscan 120, Cambridge Instruments). Raman imaging has been performed with a microRaman spectrometer Renishaw Invia reflex with the WIRE software. The laser has a wavelength of $532 \mathrm{~nm}$ and the applied power is less than $100 \mu \mathrm{W}$ in order to prevent any possible sample degradation. The selected samples were observed with a $50 \times$ objective, the analyzed section covers a surface area of $3 \mu \mathrm{m} \times 3 \mu \mathrm{m}$, while the depth of investigation is $2 \mu \mathrm{m}$. Reference spectra have been obtained in [30] for each individual phase of the corrosion products, on samples synthesized in the laboratory or on commercial powders.

The analyzed samples generally display areas with a superposition of different phases, each phase being characterized by different response intensities and overlapped peaks. The CorATmos software $[4,27]$ employed during our 
experiments overcomes this difficulty by using a semi-quantitative analysis, which involves adjusting each spectrum with a combination of reference spectra. In this way, semi-quantitative localization mappings can be drawn for each phase.

\subsubsection{Vickers Micro-indentation}

The micro-indentation tests on corrosion product layers have been described in [3], we recall briefly the principle of those tests. A depth sensing microindentation apparatus (V-G 60 Micro Hardness Tester from CSM Instruments) has been employed for the characterization of local mechanical properties. Quasi-static loadings comprised between 0.03 and $30 \mathrm{~N}$ can be applied at the tip of the Vickers diamond indenter/probe, with a load resolution of $0.3 \mathrm{mN}$ and a resolution in displacement of $1 \mathrm{~nm}$, the microscope magnification ratio being equal to 5 or 50 [31]. From Oliver and Pharr's method [32] commonly employed in the exploitation of the load/depth curves, we identify at the level of each impression a local elasticity modulus and a local hardness. In addition, the impression produced by the Vickers probe having a side length approximately equal to $10 \mu \mathrm{m}$, the effect of nanoporosity (of pore access diameter comprised between 3 and $30 \mathrm{~nm},[14]$ ) is indirectly taken into account in the measurement of the local mechanical properties of corrosion products [2]. For each sample investigated, between 50 and 150 impressions have been recorded. 


\subsubsection{Statistical analysis}

The local mechanical phase properties (elasticity modulus and hardness) have been interpreted using the statistical indentation method. This experimental analysis of phase properties, originally developed for cement based materials and extended to structural ceramics [28, 33], is carried out with the aid of Gaussian Mixture Modeling. allow to test whether the apparent groupings are Mixture models assume that data originate from a source containing several populations. Each population group (cluster) is modeled in a separate way (with its proper average, its covariance ...). Among the existing mixture models, the Gaussian Mixture Model employed consists in a density probability of a parameter function modelled by a weighted sum of N Gaussians. According to [33], the Gaussian law is well adapted to represent the dispersions of indentation testing on a material with strong microstructural heterogeneities. The statistical analysis consists in determining the average, the variance and the range of each Gaussian by estimating the Maximum Likehood through the algorithm of Expectation-Maximization [28, 34]. The number of components is identified by relying on the Bayesian Information Criterion proposed by [35] and employed by [28] in the exploitation of nanoindentation tests on fired clay brick. 

total number of components:

$$
f(\mathbf{x} ; \phi)=\sum_{j=1}^{g} \pi_{j} f_{j}\left(\mathbf{x} ; \varphi_{j}\right)
$$

233

234 vectors $\mathbf{x}_{i}, \mathbf{x}$ designating the set of vectors $\mathbf{x}_{i}$.

$$
\mathbf{x}_{i}=\left[E_{i}, H_{i}\right] .
$$

total number of components:

33

$$
\sum_{j=1}^{g} \pi_{j}=1, \pi_{j} \geq 0
$$

$$
0 \leq \pi_{j} \leq 1
$$
$f_{i}$.

The input experimental data are the set of values taken by the elasticity modulus and the hardness at each indentation point, represented by the

The density function can be written as the sum of the density functions of each phase, weighted by their respective proportions, $g$ representing the

$\pi_{j}$ is the proportion of component $j$. The vector $\phi$ contains all the unknown parameters: $\phi=\left[\pi_{1}, \ldots, \pi_{g}, \varphi_{1}, \ldots, \varphi_{g}\right]$ and $\varphi_{\mathbf{j}}=\left[\mu_{j}, \Sigma_{j}\right]\left(\mu_{j}\right.$ is the average vector of phase $j$ and $\Sigma_{j}$ the covariance matrix), the parameters of the law

The function of density of components takes the form of a bivariate Gaussian distribution:

$$
f_{i}\left(\mathbf{x}_{j} ; \varphi_{i}\right)=\frac{1}{\sqrt{2 \pi}}(|\boldsymbol{\Sigma}|)^{-1 / 2} \exp \left\{-\frac{1}{2}(\mathbf{x}-\mu)^{\mathrm{T}} \boldsymbol{\Sigma}^{-1}(\mathbf{x}-\mu)\right\}
$$


245

The problem is to determine the vector of unknown parameters $\phi$.

The likehood function of the unknown parameter to maximize is defined in the following way, in a logarithmic form:

$$
-\frac{1}{2} \log L(\mathbf{x} ; \phi)=\sum_{j=1}^{N} \log f(\mathbf{x} ; \phi)
$$

for $\mathrm{N}$ indentation test points in $\mathbb{R}^{2}$

The estimation of vector $\phi$ by the Maximum Likehood approach requires the resolution of the following problem:

$$
\frac{\partial \log L(\phi)}{\partial \phi}=0 .
$$

The resolution takes place iteratively. The Expectation-Maximization algorithm is employed to solve this problem with the following criteria (by default in gmdistribution.fit Matlab $\left.{ }^{\circledR}\right)$ :

1. Maximum number of iterations : 100 ;

2. Convergence criterion : $10^{-6}$.

We start with a model $\phi$ picked at random in $\mathbf{x}_{i}$ and a number of components $g$, and we estimate a new model $\bar{\phi}$ such that $L(\mathbf{x} ; \bar{\phi}) \geq L(\mathbf{x} ; \phi)$. The new model becomes the initial model for the next iteration. The iterations are continued until convergence is reached according to the chosen criterion, 
giving the averages, covariances and the proportions of the model as well as the value of the likehood function and the Bayesian Information Criterion.

In order to determine the number of components which is the most appropriate to the experimental data, gmdistribution.fit is evaluated several times by using the same input data $\mathbf{x}_{i}$, while the number of components $g$ is varied. The Bayesian Information Criterion is recorded at each computation. The most appropriate number of components $g$ is the number corresponding to the highest probability of minimization of the following criterion:

$$
-2 \log L_{g}(\widehat{\phi})+k_{g} \log N,
$$

\section{Experimental results}

\subsection{Characterization of the composition}

\subsubsection{Natural corrosion layers}

The analysis of the crystalline phases present in the samples of the archeological artefacts has been partly presented in [3]. Experimental investigations of $[14,16,30,36]$ have shown that after a corrosion period of about 50 years, the same corrosion products may be encountered during atmospheric corrosion, independently from the hydraulic binder composition : the ferric oxyhydroxides are mainly goethite $\alpha$-Fe00H and lepidocrocite $\gamma$-FeOOH, crossed 
by oxide marblings composed of magnetite $\mathrm{Fe}_{3} \mathrm{O}_{4}$ and possibly maghemite $\gamma-\mathrm{Fe}_{2} \mathrm{O}_{3}$. Raman microspectrometry in Figure 4, comprising more than 600 points, displays well-defined spectra of goethite and lepidocrocite which compare well with the reference spectra displayed in Figure 3)(a and b). Magnetite has also clearly been identified in several regions, Figure 3(c). However, it is more difficult to distinguish magnetite from maghemite or ferrihydrite owing to the occurrence of mixtures of several phases, Figure 4(e,f) and Figure 3(c). Certain Rama spectra are characterized by an enlarged peak at 700 $\mathrm{cm}^{-1}$, which may be representative of the occurrence of different oxides, such as magnetite, maghemite or ferrihydrite, and have been exploited with the semi-quantitative CorATmos procedure, Figure 3(d). SEM-EDS mappings show that the overall composition consists mainly of iron and oxygen, with a mass percentage of iron comprised between $60 \%$ and $72 \%$. The latter results are in agreement with the stoichiometric formulas of the phases determined by coupling Raman spectroscopy with CorATmos semi-quantitative analysis, Table 1. Based on the Raman spectra and the SEM EDS compositions, we have identified two main classes of phases in the ancient ferrous artefacts: the oxyhydroxides (goethite and lepidocrocite) and the oxides (magnetite, maghemite, ferrihydrite), Figure 4.

Concerning the distribution of crystalline phases, the semi-quantitative analysis with CorATmos indicates that the dark matrix is essentially composed of goethite, which may be mixed with other phases. We also encounter lepidocrocite in a very localized way. The regions of clear marblings, char- 
acterized by a higher proportion of iron, correspond to a mixture of oxides such a magnetite or maghemite.

A Raman cartography of 360 spectra has been performed on the sample originating from the 50 years-old concrete building. The spectra of the main phases are illustrated in Figure 5. The main products encountered are goethite, and a phase which is likely a mixture of ferrihydrite and maghemite [2].

\subsubsection{Corrosion under impressed current method}

A Raman microcartography of 120 points has been realized for the sample of corrosion synthetized under imposed current. The investigated zone is mainly composed of ferrihydrite with localized inclusions of akaganeite, Figure 6.

\subsubsection{Corrosion under controlled saline environment}

Raman cartographies have been made for the 14 years-old (LMDC14) and 25 years-old (LMDC25) samples of concrete beams corroded under salt fog, comprising 376 and 390 spectra respectively. The distribution of the various phases resulting from the CorATmos interpretation of Raman mappings is illustrated in Figure 7. The main phases of the 14 years-old sample are goethite corresponding to the dark matrix, a mixture of maghemite and ferrihydrite in the clear marblings, with local inclusions of akaganeite.

The 25 years-old sample is composed mainly of goethite (dark matrix) and marblings of magnetite/maghemite, with a clearer distribution than the 
14 years-old sample, as illustrated in Figure 8 on the Raman cartography results interpreted with CorATmos.

\subsection{Characterization of the local mechanical properties}

\subsubsection{Vickers depth sensing micro-indentation}

Figure 9 synthetizes the micro-indentation results, the values of local hardness $H$ and elasticity modulus $E$ identified from each impression are reported for the whole set of investigated corrosion layers. The Young's modulus and hardness values reported cover a wide range, varying from 1 to $12 \mathrm{GPa}$ for $H$, and from 30 to $159 \mathrm{GPa}$ for $E$. As expected, $H$ increases with $E$. We also observe that the obtained values are gathered along a narrow range, with an average ratio $\frac{H}{E} \approx 0.0628$. Such a ratio describes the relative resistance of plastic and elastic strains. A similar $\frac{H}{E}$ ratio for the various corrosion products suggests that the deformation mechanisms and the chemical bonds may be similar for the different corrosion layers.

Nevertheless the various corrosion products investigated present distinct ranges of Young's modulus values.

The corrosion layers developed under carbonatation in the long term (50 years for the concrete building and 660 years for the ancient artefacts) present the highest values of elasticity modulus, comprised between 64 and 159 GPa. We notice the strong similitude of the results obtained with these two types of samples, however for the sample corroded during 50 years we observe a higher proportion of local elasticity moduli close to 90 GPa. The average 
Young's modulus deduced from 115 indentation points is equal to $99 \mathrm{GPa}$ for the corrosion taken on the reinforced concrete building. For the ferrous artefact, the average Young's modulus reaches the value of $116 \mathrm{GPa}$, based on 91 indentation points. In [18], nano-indentation on a corroded steel rebar in a reinforced concrete port in service for decades has resulted in a variable Young's modulus depending on the sample orientation : $61 \mathrm{GPa}$ and $86 \mathrm{GPa}$ for the samples parallel and orthogonal to the steel bar respectively. The latter results, identified at the depth range of 0.6 to $1.6 \mu \mathrm{m}$, are very similar to the local elasticity moduli identified in the present study for the corroded rebar at the depth range of $2 \mu \mathrm{m}$.

The corrosion products synthetized under imposed current are characterized by lower values of Young's modulus and hardness, as compared to corrosion products formed under natural conditions. The average of elasticity moduli obtained from 49 points of indentation is equal to $56 \mathrm{GPa}$, with a standard deviation of $9 \mathrm{GPa}$. In [18], nano-indentation has also been performed on corrosion products generated by impressed current, resulting in fluctuations of the measured elasticity modulus owing to the thinness of the rust layer. The average Young's modulus is estimated to be $47 \mathrm{GPa}$, and is of the same order of magnitude as the value identified in our study.

The number of indentation grid points made on the three samples corroded in a saline environment (LMDC3, LMDC14 and LMDC25) varies between 46 and 77 points. The results obtained for the elasticity modulus and the hardness present an important dispersion, with elasticity moduli that 
may be very low. The hardness is comprised between 1 and $11 \mathrm{GPa}$, while Young's modulus is comprised between 30 and 150 GPa. Consequently, the statistical analysis could not be performed under such conditions, and additional indentation grids would be necessary. We observe that $H$ and $E$ seem to increase with the age of the sample. LMDC3 and LMDC14 present an important number of impressions leading to values lower than $(H=4 \mathrm{GPa}$; $E=70 \mathrm{GPa}$ ), which may be due to the occurrence of ferrihydrite.

The results obtained from the combined micro-indentation and Raman analysis are gathered in Table 3 .

\subsubsection{Statistical interpretation of micro-indentation results}

For the natural corrosion products, the indentation grids have been performed on the regions mapped with Raman spectroscopy beforehand. We have observed in [3] that if we retain the indentation results corresponding to a percentage of the main phase higher than $85 \%$, we may distinguish between two groups. If goethite is the dominant phase, the elasticity modulus is comprised between 92 and $111 \mathrm{GPa}$, whereas if magnetite/maghemite is the main component, the elasticity modulus takes higher values, comprised between 107 and 158 GPa. However, the comparison between the phase proportions and the corresponding elasticity moduli do not allow us to associate an average value of Young's modulus to a given phase. Indeed, the proportions of the various phases vary for each impression, while the part played by nanoporosity is difficult to assess. For this reason, the average val- 
ues of elasticity moduli per phase have been determined using a statistical analysis based on a Gaussian mixture model, by considering for each impression the couple $(H, E)$. Figure 10 details the statistical analysis performed on a grid of 91 indentation points from the archeological analogues. We distinguish two indentation groups displaying different Young's moduli and hardness values. Each of these groups corresponds to specific compositions of corrosion products.

Table 2 summarizes the results of the statistical study concerning the number of representative phases, their relative proportions and corresponding Young's moduli. This study has been conducted on the corroded rebar from the reinforced concrete building, the ferrous artefact and the artificial corrosion developped under impressed current. We find two groups with statistically distinguishable properties for the corroded rebar and the ferrous artifacts, as well as for the artificial corrosion.

For the corrosion synthetized under impressed current, we observe that phase 1 with the lower elasticity modulus (ferrihydrite) is largely dominant with respect to the second phase. The second phase presents an elasticity modulus lower than the modulus associated with goethite, which may indicate a mixture of phases including goethite and ferrihydrite. For the corrosion developed under atmospheric conditions, the analysis highlights similar average values of Young's modulus for the dark matrix regions mainly composed of goethite (phase 1). According to Raman analysis, phase 2 corresponds to the marblings of maghemite/ferrihydrite, the statistical analysis gives an average 
elasticity modulus of 113 GPa for the concrete building, and a higher value of 139 GPa for the archeological artefact. The discrepancy between those values could be due to a higher crystallization level in the older sample. The statistical analysis also provides the various proportions of both samples, which are close to the proportions inferred from the Raman spectroscopy coupled with CorATmos [2]. For instance, we obtain the following proportions for the main components of the concrete building sample with CorATmos: $69 \%$ for phase 1 and $31 \%$ for phase 2 . Our study tends to show that the goethite phase is predominant for the two samples of natural corrosion. Furthermore, the older sample (aged 660 years) presents a smaller proportion of goethite as compared to the concrete building (aged 50 years).

\section{Discussion}

\subsection{Typical layouts of corrosion products and associated elasticity moduli}

We can conclude that the various samples present distinct compositions. The early-age corrosion products developed in the laboratory under imposed current are mainly composed of ferrihydrite which average Young's modulus is rather low, around $56 \mathrm{GPa}$. The study of the local elasticity modulus of the different corrosion layers has evidenced the fact that the dark matrix of goethite presents a nearly constant value of Young's modulus, between 90 and 95 GPa. The clear marblings are characterized by a composition which differs for each sample, and imply an evolution of the local mechanical properties. 
The sample originating from a 50 years-old concrete building is composed of a dark matrix consisting mainly of goethite, and clear marblings corresponding to a mixture of ferrihydrite and maghemite with an average Young's modulus of $113 \mathrm{GPa}$. The sample taken from the historical monument and aged over 660 years displays a dark matrix composed of goethite and clear marblings of magnetite/maghemite, with an elasticity modulus around 140 GPa. The samples corroded under a controlled saline environment offer the same kind of phase distribution, characterized by a main phase of goethite and marblings of variable composition : mainly ferrihydrite and local traces of akaganeite owing to chloride ions for the 3 years old sample, a mixture of maghemite and ferrihydrite and traces of akaganeite for the 14 years-old sample, and a mixture of magnetite and maghemite for the 25 years-old sample. For the sample aged 3 years, the confrontation between micro-indentation data and Raman analysis leads to the following estimates for the elasticity moduli of the phases : $94 \mathrm{GPa}$ for the goethite matrix, and $51 \mathrm{GPa}$ for the matrix of ferrihydrite. By using the same approach with the 14 years-old sample, we obtain an average value of $91 \mathrm{GPa}$ for the goethite matrix, and an average value of $59 \mathrm{GPa}$ for the marblings. For the sample of 25 years, we identify three different elasticity moduli : the value of 90 GPa may be attributed to the goethite matrix, the average value of $63 \mathrm{GPa}$ is more difficult to interpret but may be associated with ferrihydrite (not detected in our Raman mappings), while the higher value of $124 \mathrm{GPa}$ corresponds to a mixture of magnetite and maghemite and possibly ferrihydrite. The con- 
clusions of our study are in agreement with the findings of other authors. $[37,38,39]$ have assumed that the clear marblings are initially composed of ferrihydrite/feroxyhyte, which would evolve towards better crystallized phases such as magnetite/maghemite due to the progressive disappearance of less stable phases after successive reduction/oxidation cycles.

\subsection{Relation between elastic modulus and hardness}

Table 4 summarizes the average Vickers hardness measured $H$ for each phase or group of phases identified on the investigated corrosion samples. Hardness is related to the elastic and plastic properties of a material [40]. As already illustrated in Figure 9, the hardness values are rather low, which indicates a ductile behaviour with important plastic deformations [41, 40]. Similar to Young's moduli values listed in Table 3, we observe an overall increase of $H$ with the age of the specimen. As expected, we obtain from Tables 3 and 4 and Figure 9 that the Young's modulus $E$ or more precisely the shear modulus $G$ (since in our case $G=\frac{E}{2(1+0.3)}$ ) and $H$ are strongly correlated, for the whole set of samples and also for the identified phases. Although no general and quantitative relationship has been established, numerous studies have been dedicated to correlate hardness with bulk modulus or shear modulus $[42,41,40]$. [41] investigate linear empirical fittings between elastic properties and hardness, and obtain that the shear modulus $G$ shows the best linear dependence on the Vickers hardness, while the bulk modulus 
cannot be linearly correlated with $H$. This fact is explained by dislocation theory : hardness depends mainly on the plastic deformation associated with the nucleation and motion of dislocations $[41,40]$, which may be more easily caused by shear deformation than by volume change. We also observe that the relative incertitude concerning both $E$ and $H$ has a tendency to decrease with the age of the sample. The standard deviation measured on the different samples is not negligible and is more important than for Young's modulus, this may be explained by the fact that Vickers hardness is not an intrinsic property, and is strongly affected by extrinsic factors such as surface defects, local stress field, and morphology [41, 40]. In our case the effect of these factors are amplified by the strongly heterogeneous and evolving microstructure. However, the relative decrease of the data scatter is consistent with the fact that hardness is also strongly related to intrinsic properties such as bond strength and cohesive energy $[42,41,40]$, which may increase with the age of the sample as we evolve towards better crystallized phases. Vickers hardness is also related to crystal structure, which is more stable for the older samples. Finally, $\frac{H}{E}$ ratio or resilience describes the relative resistance to elastic and plastic deformation, and is potentially predictive of the limit yield strain to failure, fracture toughness, and wear resistance [43]. From Tables 3 and 4, we obtain similar $\frac{H}{E}$ ratios for all the identified phases, from which we may deduce that the goethite matrix and the marblings (of varying composition with age) have to sustain similar mechanical wear stress, and there is no privileged zone for crack initiation at the mesoscopic scale. 


\subsection{Time evolution of the phase composition and mechanical properties}

From the identification of the local elasticity properties presented in this paper, we can also formulate the assumption of a progressive increase of the mechanical properties of the corrosion samples concurrently with the evolution of the phases constituting the marblings: starting from ferrihydrite $(\mathrm{E}=56 \mathrm{GPa})$ in the early-age samples, we go through goethite $(E \simeq 92-95$ $\mathrm{GPa})$ and a mixture of maghemite/ferrihydrite $(E \simeq 113 \mathrm{GPa})$ in the 50 years-old sample, before reaching the phase of magnetite/maghemite $(E \simeq$ $139 \mathrm{GPa}$ ) in the older samples. Consequently, the average Young's modulus would increase with the age of the corrosion product layers, from about 50 GPa for early-age samples to $140 \mathrm{GPa}$ for samples aged several hundred years. As the conditions of corrosion differ from one sample to the other, we cannot directly compare the whole set of results of physico-chemical and micromechanical analysis conducted on the various samples. However, the study of samples corroded under saline environment tends to corroborate the assumption of an increase of the elasticity modulus with the age of the corrosion product layers. The average value of Young's modulus is plotted in Figure 11 with respect to the age of the sample. Based on the limited data available, it may be interesting to notice that there are two regions: the elasticity modulus increases abruptly during the first 25 years of ageing, and tends to stabilize afterwards with a very moderate increase. 


\section{Conclusion}

Using micro-indentation testing coupled with Raman microspectrometry (and CorATmos semi-quantitative analysis) and statistical analysis on the same impressed zones, we have been able to relate the local mechanical properties (elasticity modulus and hardness) of steel corrosion products to typical phase distribution layouts. The main conclusions are the following ones:

1. The microstructure of the investigated corrosion samples is composed of different phases which may present themselves as mixtures at the mesoscopic scale. A dark matrix composed essentially of goethite is crossed by marblings of varying composition.

2. The local Vickers hardness varies between 1 and $12.1 \mathrm{GPa}$, while the local elasticity modulus varies between 30 and $160 \mathrm{GPa}$ on the whole set of indented samples (448 impressions). To our knowledge, the hardness and Young's modulus distributions identified at the level of the elementary corrosion products constitute a unique set of data with no equivalent in the published literature.

3. We have identified typical elasticity and hardness values per phases. The lowest values of Young's modulus and hardness are associated with ferrihydrite, and the highest $E$ and $H$ values have been measured on marblings of magnetite/maghemite.

4. The $\frac{H}{E}$ ratio is quite similar for all the encountered phases, which may 
indicate that the matrix and the marblings can sustain similar mechanical fatigue stress, and that there is no preferred zone for crack initiation.

5. The corrosion products may evolve with time: the corrosion under impressed current contains mainly ferrihydrite; apart from goethite, chloride corrosion is composed of ferrihydrite, maghemite/ferrihydrite, and magnetite/maghemite/ferrihydrite for the samples aged 3, 14 and 25 years respectively; the corroded rebar aged 50 years presens a matrix of goethite with marblings of maghemite and ferrihydrite; and for the ferrous artefacts aged 660 years, the goethite matrix is crossed by marblings of magnetite and maghemite. The time evolution towards better crystallized phases is associated with an increase of $E$ and $H$.

\section{Acknowledgements}

This study is part of a thesis funded by ANDRA, we thank in particular X. Bourbon. We also thank V. L'Hostis (CEA/DEN, LECBA) and D. Neff (CEA/DSM) for their precious advices during the ph.D thesis of the first author. The assistance of F. Datcharry (CEA-LECA) during microindentation testing is also gratefully acknowledged, as well as the assistance of E. Amblard (CEA-LECBA) and A. Desmoulins (CEA-LAPA) regarding micro-spectrometry Raman testing performed at LADIR laboratory of CEASaclay. We also express our deepest thanks to professor R. Franois (LMDC Toulouse, France) for kindly providing the samples of corrosion under saline 
environment.

Finally, the authors wish to thank the anonymous reviewers for the relevance of their remarks, which have contributed greatly in improving the paper.

\section{References}

[1] Andra, Dossier 2005 HAVL Argile Synthese - Evaluation de la faisabilité du stockage géologique en formation argileuse, Agence Nationale pour la Gestion des Déchets Radioactifs, Chtenay-Malabry, France, (2005) (in French).

[2] A. Dehoux, Propriétés mécaniques des couches de produits de corrosion a l'interface acier/béton, Ph. D thesis, UPMC Sorbonne Universités, Paris, 2012 (in French). Available online at https://hal.archivesouvertes.fr/file/index/docid/828155/filename/these.pdf.

[3] A. Dehoux, F. Bouchelaghem, Y. Berthaud, D. Neff, V. L'Hostis, Micromechanical study of corrosion product layers. Part I: Experimental characterization, Corrosion Science 54 (2012) 52-59.

[4] J. Monnier, D. Neff, S. Reguer, P. Dillmann, L. Bellot-Gurlet, E. Leroy, E. Foy, L. Legrand, I. Guillot, A corrosion study of the ferrous medieval reinforcement of the Amiens cathedral. Phase characterisation and localisation by various microprobes techniques, Corrosion Science 52 (2010) 695-710. 
[5] D. Feron, D. Crusset, J.-M. Gras, D.D. Macdonald, Prediction of Long Term Corrosion Behaviour in Nuclear Waste Systems, Science and Technology Series, ANDRA, Chatenay-Malabry, 2004.

[6] D. Neff, M. Saheb, J. Monnier, S. Perrin, M. Descostes, V. L'Hostis, D. Crusset, A. Millard, P. Dillmann, A review of the archaeological analogue approaches to predict the long-term corrosion behaviour of carbon steel overpack and reinforced concrete structures in the French disposal systems, Journal of Nuclear Materials 402 (2010) 196-205.

[7] W. Miller, Geological Disposal of Radioactive Wastes and Natural Analogues: Lessons from Nature and Archaeology, Pergamon, 2000.

[8] S. Caré, Q.T. Nguyen, V. L'Hostis, Y. Berthaud, Mechanical properties of the rust layer induced by impressed current method in reinforced mortar, Cement and Concrete Research 38 (2008) 1079-1091.

[9] Q.T. Nguyen, Études expérimentales et théoriques de l'effet de la corrosion sur la fissuration du béton et le comportement global des structures en béton armé, Ph.D. thesis, Université Pierre et Marie Curie, Paris, 2006.

[10] A. Castel, R. Francois, G. Arliguie, Mechanical behaviour of corroded reinforced concrete beams. Part I : experimental study of corroded beams, Materials and Structures 33 (2000) 539-544. 
[11] R. Francois, Bton arm : corrélation entre fissuration et corrosion, Ph.D thesis, Université Paul Sabatier de Toulouse, France, 1987.

[12] T. Vidal, R. A. Castel, R. Franois, Corrosion process and structural performance of a 17 year old reinforced concrete beam stored in chloride environment, Cement and Concrete Research 37 (2007) 1551-1561.

[13] K. Suda, S. Misra, K. Motohashi, Corrosion products of reinforcing bars embedded in concrete, Corrosion Science 35 (1993) 1543-1549.

[14] W.J. Chitty, P. Dillmann, V. L'Hostis, C. Lombard, Long-term corrosion resistance of metallic reinforcements in concrete - a study of corrosion mechanisms based on archaeological artefacts, Corrosion Science 47 (2005) 1555-1581.

[15] W.J. Chitty, Etude d'analogues archologiques pour la prvision de la corrosion plurisculaire des armatures du bton arm: caractrisation, mcanismes et modlisation, Ph.D thesis, Universit de Technologie de Compigne, France, 2006.

[16] W.J. Chitty, P. Berger, P. Dillmann, V. L'Hostis,, Long-term corrosion of rebars embedded in aerial and hydraulic binders Mechanisms and crucial physico-chemical parameters, Corrosion Science 50 (2008) 21172123.

[17] P. Dillmann, F. Mazaudier, S. Hoerl, Advances in understanding atmospheric corrosion of iron. i. Rust characterization of ancient artefacts 
exposed to indoor atmospheric corrosion, Corrosion Science 46 (2004) 1401:1429.

[18] Y. Zhao, H. Dai, W. Jin A study of the elastic moduli of corrosion products using nano-indentation techniques, Corrosion Science 65 (2012) 163-168

[19] C. Andrade, C. Alonso, F.J. Molina, Cover cracking as a function of bar corrosion: part 1 - experimental test, Materials and Structures 26 (1993) 453-464

[20] F.J. Molina, C. Alonso, C. Andrade, Cover cracking as a function of rebar corrosion: part 2 - numerical model, Materials and Structures 26 (1993) 532-548.

[21] A. Ouglova, Y. Berthaud, M. Franois, F. Foct, Mechanical properties of an iron oxide formed by corrosion in reinforced concrete structures, Corrosion Science 48 (2006) 3988-4000.

[22] Y. Zhao, H. Dai, H. Ren, W. Jin, Experimental study of the modulus of steel corrosion in concrete port, Corrosion Science 56 (2012) 17-25.

[23] K. Lundgren, K. A model for 3D-analyses of bond between corroded reinforcement and concrete, Proceedings of the Sixth Int. Conference, Concreep-6@MIT, Ulm et al. (Eds.), Elsevier, The Netherlands (2001) 485-490. 
[24] B. Le Neindre, Coefficients d'élasticité, Techniques de l'ingénieur, Traité Constante Physico-chimiques, Reference K486 10 december 1991 (in French).

[25] G.V. Samsonov, The Oxide Handbook, IFI/PLENUM, New York, 1973.

[26] P. Hosemann, J.G. Swadener, J. Welch, N. Li, Nano-indentation measurement of oxide layers formed in LBE on F/M steels, Journal of Nuclear Materials 377 (2008) 201205.

[27] J. Monnier, Corrosion atmosphérique sous abri d'alliages ferreux historiques : caractérisation du systeme, mécanismes et apport a la modélisation, Ph.D thesis, Université Paris-Est, France, 2008.

[28] Krakowiak K.J., Assessment of the mechanical microstructure of masonry clay brick by nanoindentation, Ph.D Thesis, Universidade do Minho, Escola de Engenharia Civil, 2011.

[29] R. Zhang, Phase d'initiation et propagation de la corrosion dans les structures en béton armé et leurs conséquences sur la durée de vie, Ph.D thesis, Université Paul Sabatier de Toulouse, France, 2008.

[30] D. Neff, L. Bellot-Gurlet, P. Dillmann, S. Reguer, L. Legrand, Raman imaging of ancient rust scales on archaeological iron artefacts for longterm atmospheric corrosion mechanisms study, Journal of Raman Spectroscopy 37 (2006) 1228-1237. 
[31] Handbook on Instrumented Indentation, CSM Instruments SA, Switzerland, 2008.

[32] WW.C. Oliver, G.M. Pharr, An improved technique for determining hardness and elastic modulus using load displacement sensing indentation experiments, Materials Research Society 7 (1992) 1564-1583.

[33] F.J. Ulm, Experimental and theoretical multiscale analysis of materials and structures, Technical Report, Summer Course of the International Center for Mechanical Sciences, Udine, Italy, 2011.

[34] G. MacLachlan, D. Pell, Finite Mixture Models, Wiley Series in Probability and Statistics, Wiley Interscience Publication, 2000.

[35] G. Schwartz, Estimating the dimension of a model, The Annals of Statistics, 6 (1978) 461-464.

[36] G.S. Duffo, W. Morris, I. Raspini, C. Saragovi, A study of steel rebars embedded in concrete during 65 years, Corrosion Science 46 (2004) 21432157.

[37] A. Demoulin, C. Trigance, D. Neff, E. Foy, P. Dillmann, V. L'Hostis, The evolution of the corrosion of iron in hydraulic binders analysed from 46-and 260-year-old buildings, Corrosion Science 52 (2010) 3168-3179.

[38] V. Lair, H. Antony, L. Legrand, A. Chausse, Electrochemical reduction of ferric corrosion products and evaluation of galvanic coupling with iron, Corrosion Science 48 (2006) 2050-2063. 
[39] M. Stratmann, K. Bohnenkamp, H.-J. Engell, An electrochemical study of phase transitions in rust layers, Corrosion Science 23 (1983) 969-985.

[40] J. Haines, J.M. Léger, G. Bocquillon, Synthesis and design of superhard materials, Annual Review Material Research 31 (2003) 1-23.

[41] X. Jiang, J. Zhao, X. Jiang, Correlation between hardness and elastic moduli of the covalent crystals, Computational Materials Science 50 (2011) 2287-2290.

[42] Y.W. Bao, W. Wang, Y.C. Zhou, Investigation of the relationship between elastic modulus and hardness based on depth-sensing indentation measurements, Acta Materialia 52 (2004) 5397-5404.

[43] M.F. Ashby, D.R.H. Jones, Engineering Materials 2, (1998) Butterworth Heineman, Oxford. 


\section{List of figures}

Figure 1. Investigated samples. (a) Sample of reinforced concrete building aged 50 years; (b) ancient ferrous artefact aged 660 years; (c) corrosion synthetized under imposed current. Corrosion developed in the laboratory under controlled saline conditions : (d) 3 years-old sample; (e) 14 years-old sample; (f) 25 years-old sample.

Figure 2. Image obtained by X-ray tomography on a sample of ancient ferrous artefact aged 660 years.

Figure 3. Raman microspectrometry analysis. (a) Reference goethite spectrum. (b) Reference lepidocrocite spectrum; (c) Reference spectra obtained in [27]; (d) : Semi-quantitative analysis on the archeological artefact by combination of reference spectra using CorATmos program.

Figure 4. Raman microspectrometry on archeological analogues aged 660 years. (a): Optical microscopic view of the sample; (b): enlargement of the analyzed zone, 195 points; (c) : goethite repartition obtained with CorATmos software; (d) : magnetite/maghemite repartition obtained with CorATmos software; (e,f,g) : typical Raman spectra showing a mixture of magnetite and maghemite in the clear marblings and mainly goethite in the dark matrix.

Figure 5. Raman microspectrometry on a corroded rebar in reinforced 50 
years-old concrete building. (a): Optical microscopic view of the analyzed zone, 360 points; (b,c,d): Phase repartition of ferrihydrite, maghemite, goethite obtained with CorATmos software; (e,f,g): Typical Raman spectra on the clear marblings (ferrihydrite, maghemite) and the dark matrix (goethite).

Figure 6. Raman microspectrometry on corrosion synthetized under imposed current. (a): Optical microscopic view of the analyzed zone, 120 points; (b): Typical Raman spectrum of ferrihydrite.

Figure 7. Raman microspectrometry on a 14 years-old rebar corroded in a saline environment. (a): Optical microscopic view of the analyzed zone, 376 points; (b,c): Phase repartition of goethite obtained with CorATmos software and typical spectrum; (d,e,g): CorATmos analysis on the clear marblings (magnetite/ferrihydrite and locally akaganeite); (f,h) : Typical Raman spectra of maghemite/ferrihydrite and akaganeite.

Figure 8. Raman microspectrometry on a 25 years-old rebar corroded in a saline environment. (a): Optical microscopic view of the analyzed zone, 390 points; $(b, c, d)$ : Phase repartition of goethite, magnetite and maghemite obtained with CorATmos software; (e,f,g): Typical Raman spectra on the clear marblings (magnetite/maghemite) and the dark matrix (goethite).

Figure 9. Hardness and elasticity modulus measured on the whole set of 
747 indentation points (448 points).

748

749 Figure 10. Exploitation of indentation tests by Gaussian Mixture Models.

750 Indentation tests results and resulting Gaussian distribution for the ancient 751 artefacts.

752

${ }_{753}$ Figure 11. Variation of the average Young's modulus with the age of the 754 corroded samples.

755 
Table 1: Components of corrosion product layers and their percentages by mass of iron.

\begin{tabular}{ccc} 
Component & Chemical formula & Mass percent of iron (\%) \\
\hline Magnetite & $\mathrm{Fe}_{3} \mathrm{O}_{4}$ & 72.4 \\
Maghemite & $\gamma-\mathrm{Fe}_{2} \mathrm{O}_{3}$ & 70.0 \\
Goethite & $\alpha$-FeOOH & 62.9 \\
Lepidocrocite & $\gamma$-FeOOH & 62.9 \\
\hline
\end{tabular}

Table 2: Exploitation of the indentation grids using a Gaussian mixture model.

\begin{tabular}{cccc} 
Sample & Phases & E (GPa) & Proportion $(\%)$ \\
\hline Concrete building & 1 & $92 \pm 10$ & 66 \\
(115 points) & 2 & $120 \pm 13$ & 34 \\
\hline Archeological artefact & 1 & $95 \pm 8$ & 58 \\
(91 points) & 2 & $139 \pm 10$ & 42 \\
\hline Artificial corrosion & 1 & $51 \pm 4.7$ & 82 \\
(49 points) & 2 & $81 \pm 9$ & 18 \\
\hline
\end{tabular}


Table 3: Average Young's moduli per phase for all the investigated samples. F : Ferrihydrite; G : Goethite; Magn. : Magnetite; Magh. : Maghemite;

\begin{tabular}{ccc} 
Sample & Phase & E (GPa) \\
\hline $\begin{array}{c}\text { Artificial corrosion } \\
\text { (49 points) }\end{array}$ & $\mathrm{F}$ & $56 \pm 9$ \\
\hline $\begin{array}{c}\text { Chloride corrosion 3 years } \\
\text { (46 points) }\end{array}$ & $\mathrm{G}$ & $94 \pm 10$ \\
\hline $\begin{array}{c}\text { Chloride corrosion 14 years } \\
\text { (70 points) }\end{array}$ & $\mathrm{G}$ & $51 \pm 14$ \\
\hline Chloride corrosion 25 years & $\mathrm{G}$ & $90 \pm 10$ \\
(77 points) & $\mathrm{F}$ & $60 \pm 9 \pm 8$ \\
& Magn./Magh./F & $124 \pm 12$ \\
\hline Corroded rebar 50 years & $\mathrm{G}$ & $92 \pm 10$ \\
(115 points) & Magh./F & $120 \pm 13$ \\
\hline Ferrous artefact 660 years & $\mathrm{G}$ & $95 \pm 8$ \\
(91 points) & Magn./Magh. & $139 \pm 10$ \\
\hline
\end{tabular}

Table 4: Average Hardness values per phase for all the investigated samples. F : Ferrihydrite; G : Goethite; Magn. : Magnetite; Magh. : Maghemite;

\begin{tabular}{ccc} 
Sample & Phase & $\mathrm{H}(\mathrm{GPa})$ \\
\hline $\begin{array}{c}\text { Artificial corrosion } \\
\text { (49 points) }\end{array}$ & $\mathrm{F}$ & $3.11 \pm 1.02$ \\
Chloride corrosion 3 years & $\mathrm{G}$ & $4.76 \pm 0.80$ \\
(46 points) & $\mathrm{F}$ & $2.43 \pm 0.96$ \\
\hline Chloride corrosion 14 years & $\mathrm{G}$ & $6.26 \pm 1.33$ \\
(70 points) & Magh./F & $3.21 \pm 0.90$ \\
\hline Chloride corrosion 25 years & $\mathrm{G}$ & $6.08 \pm 1.49$ \\
(77 points) & $\mathrm{F}$ & $4.10 \pm 1.24$ \\
& Magn./Magh./F & $9.68 \pm 1.39$ \\
\hline Corroded rebar 50 years & $\mathrm{G}$ & $5.51 \pm 0.87$ \\
(115 points) & Magh./F & $8.68 \pm 1.23$ \\
\hline Ferrous artefact 660 years & $\mathrm{G}$ & $5.35 \pm 0.86$ \\
(91 points) & Magn./Magh. & $9.53 \pm 1.29$ \\
\hline
\end{tabular}



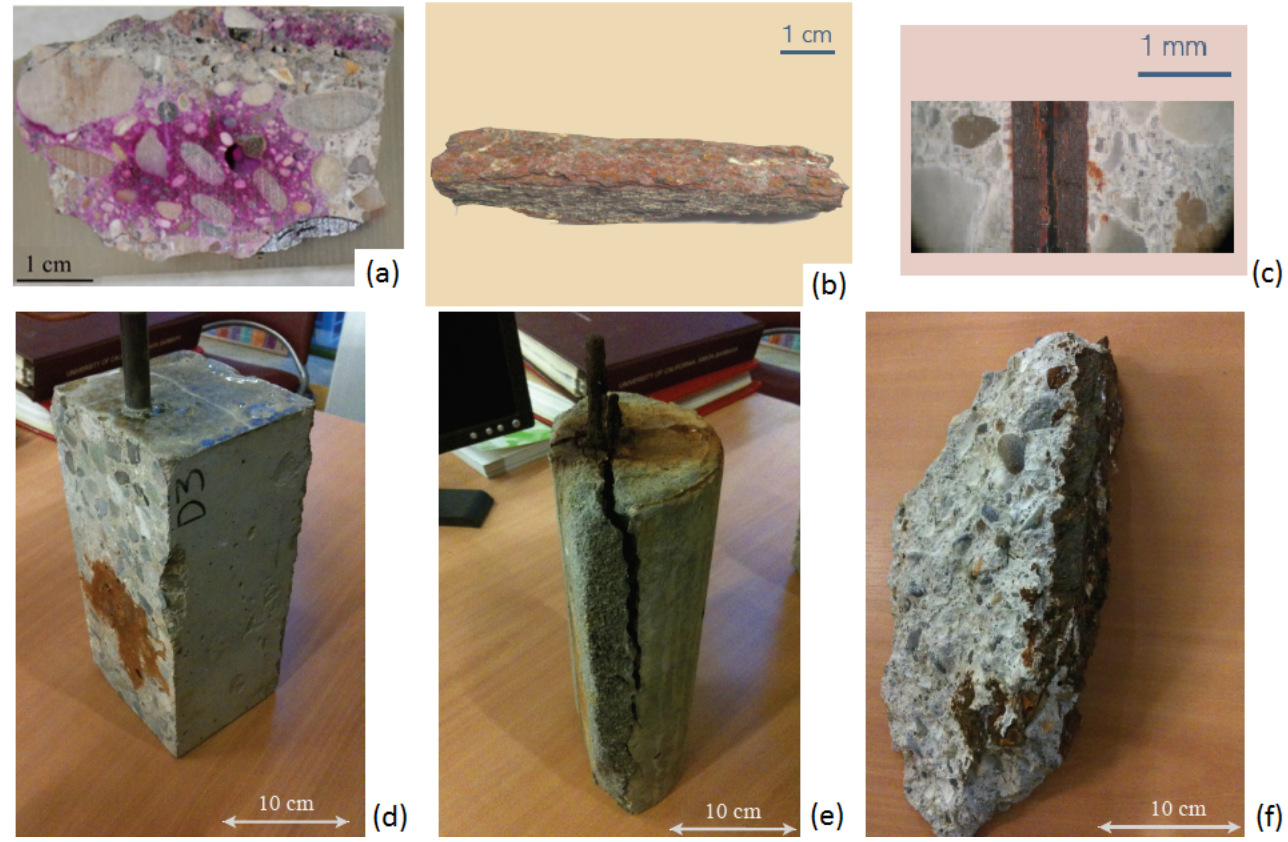

Figure 1: Investigated samples. (a) Sample of reinforced concrete building aged 50 years; (b) ancient ferrous artefact aged 660 years; (c) corrosion synthetized under imposed current. Corrosion developed in the laboratory under controlled saline conditions : (d) 3 years-old sample; (e) 14 years-old sample; (f) 25 years-old sample. 


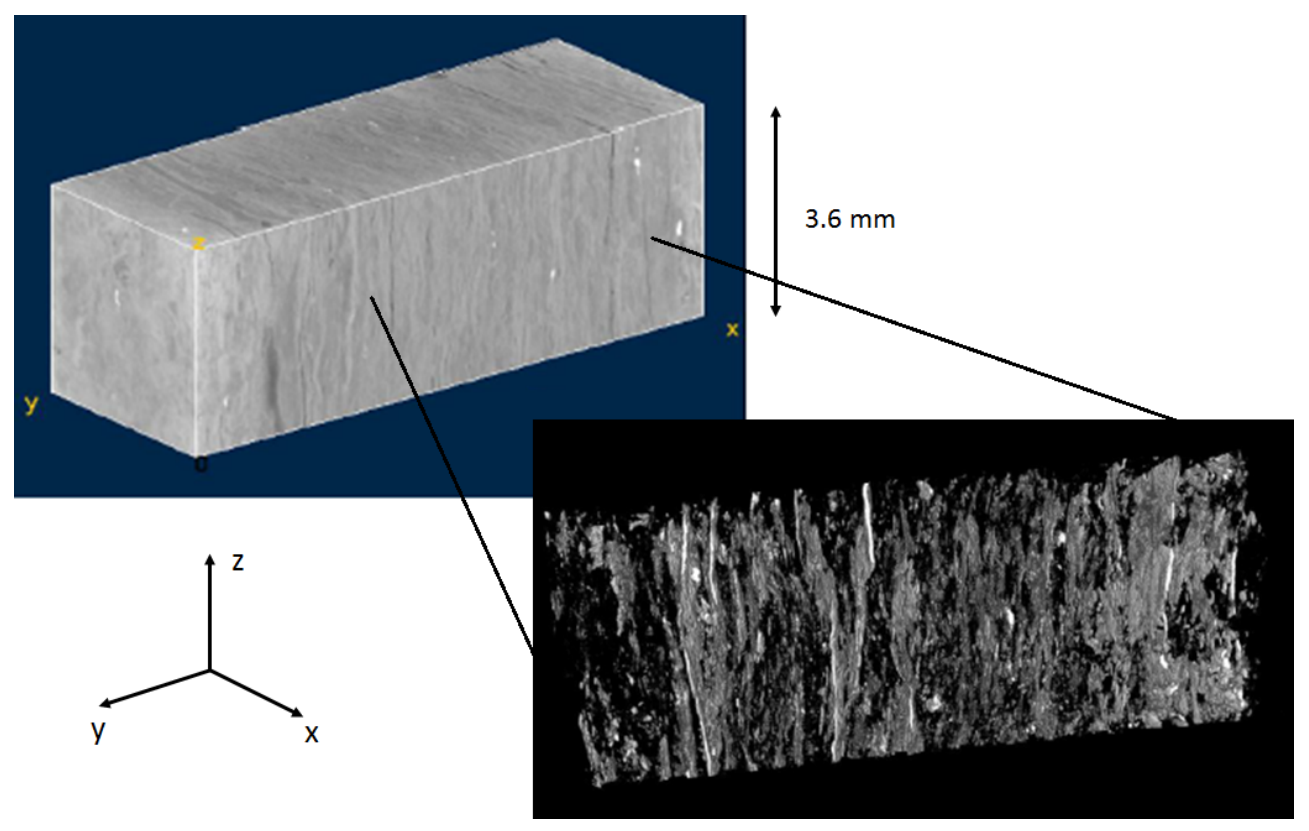

Figure 2: Image obtained by X-ray tomography on a sample of ancient ferrous artefact aged 660 years. 

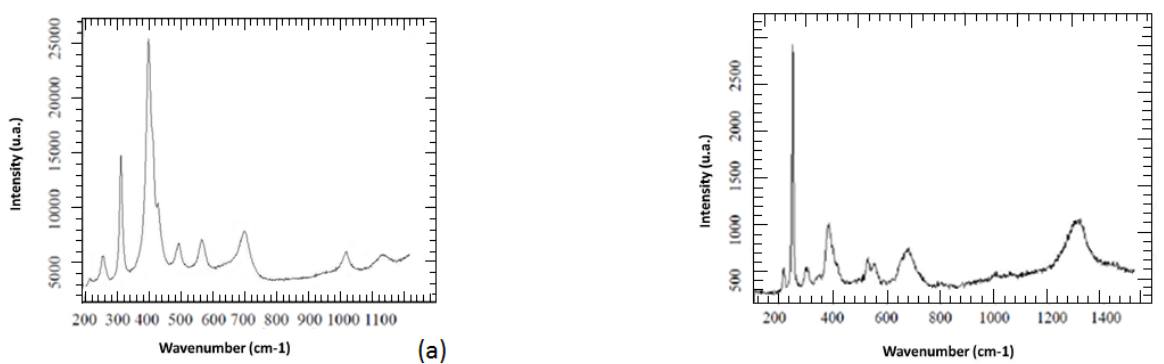

(b)
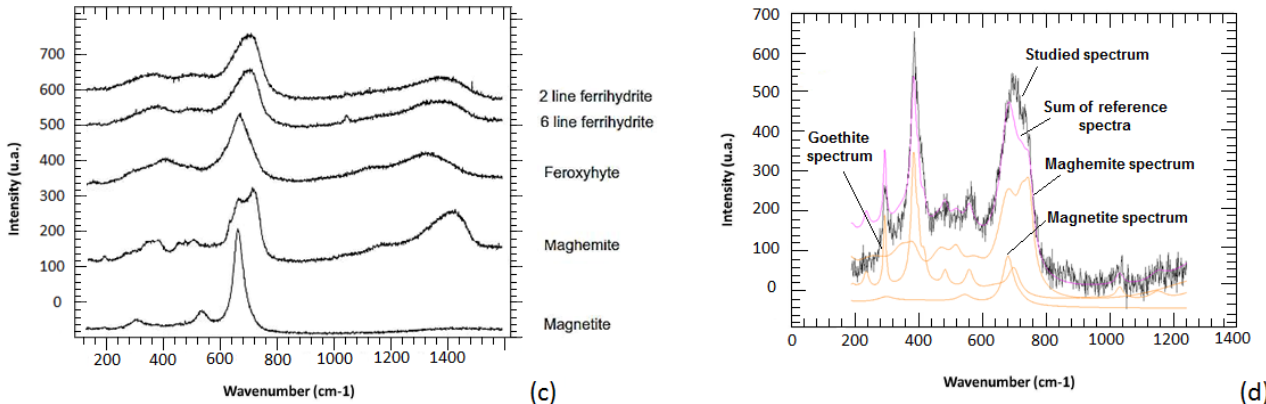

Figure 3: Raman microspectrometry analysis. (a) Reference goethite spectrum. (b) Reference lepidocrocite spectrum; (c) Reference spectra obtained in [27]; (d) : Semi-quantitative analysis on the archeological artefact by combination of reference spectra using CorATmos program. 

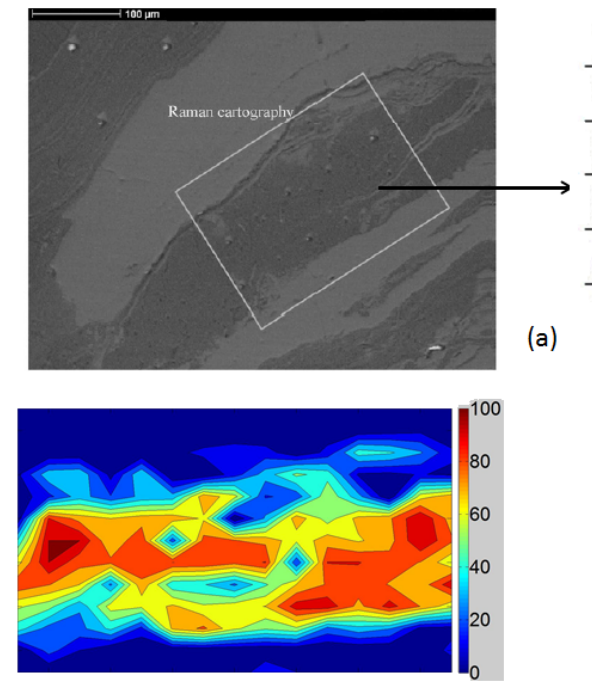

Percentage of goethite

(c)

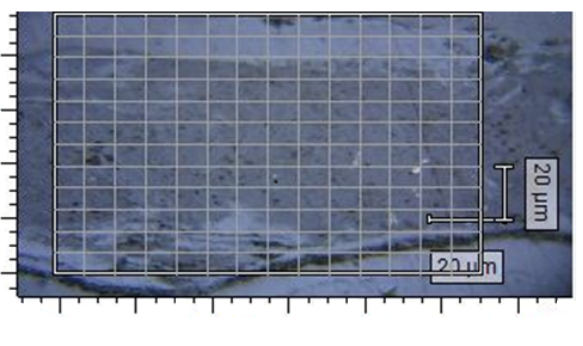

(b)
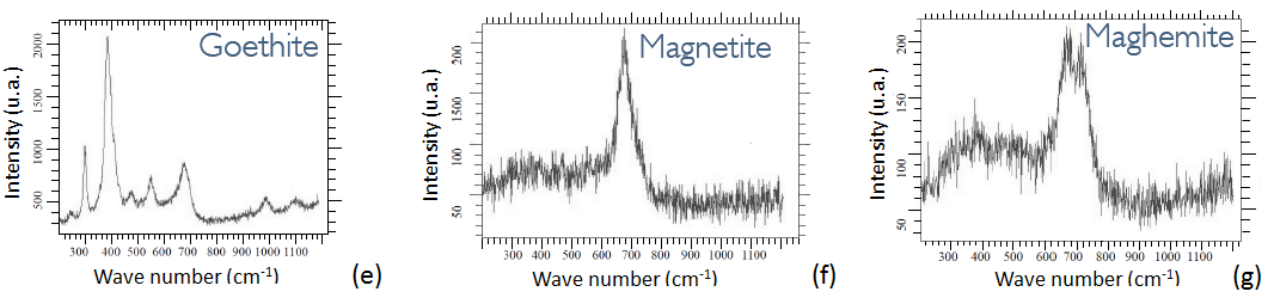

Figure 4: Raman microspectrometry on archeological analogues aged 660 years. (a): optical microscopic view of the sample; (b): enlargement of the analyzed zone, 195 points; (c) : goethite repartition obtained with CorATmos software; (d) : magnetite/maghemite repartition obtained with CorATmos software; (e,f,g) : typical Raman spectra showing a mixture of magnetite and maghemite in the clear marblings and mainly goethite in the dark matrix. 


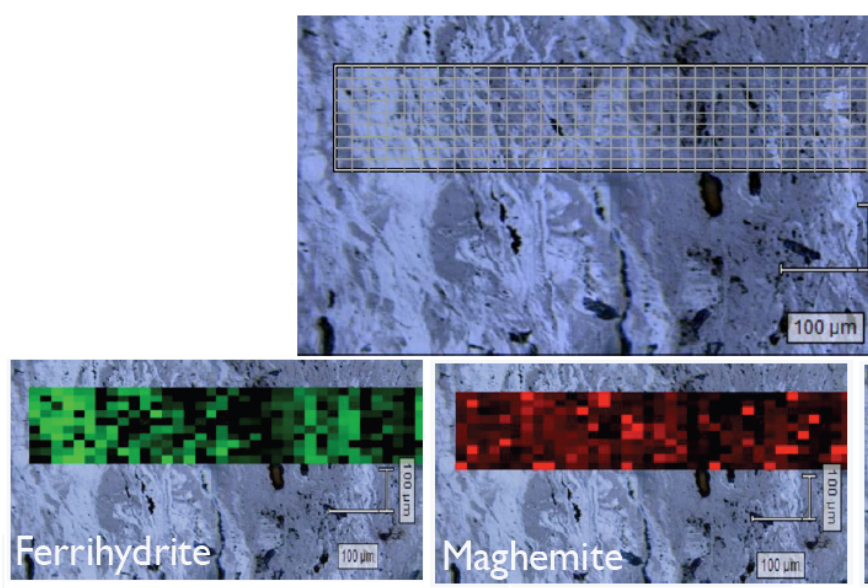

(b) (a)

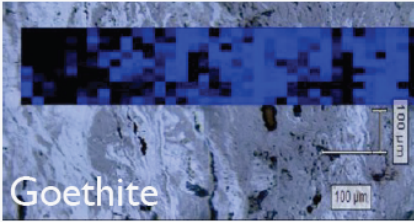

(c)

(d)

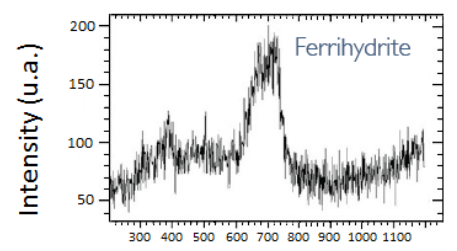

(e)

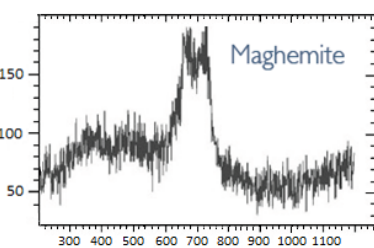

(f)

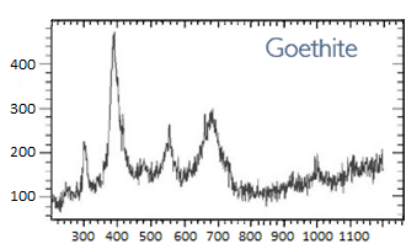

(g)

Wave number $\left(\mathrm{cm}^{-1}\right)$

Figure 5: Raman microspectrometry on a corroded rebar in reinforced 50 years-old concrete building. (a): optical microscopic view of the analyzed zone, 360 points; (b,c,d): Phase repartition of ferrihydrite, maghemite, goethite obtained with CorATmos software; $(\mathrm{e}, \mathrm{f}, \mathrm{g})$ : Typical Raman spectra on the clear marblings (ferrihydrite, maghemite) and the dark matrix (goethite). 


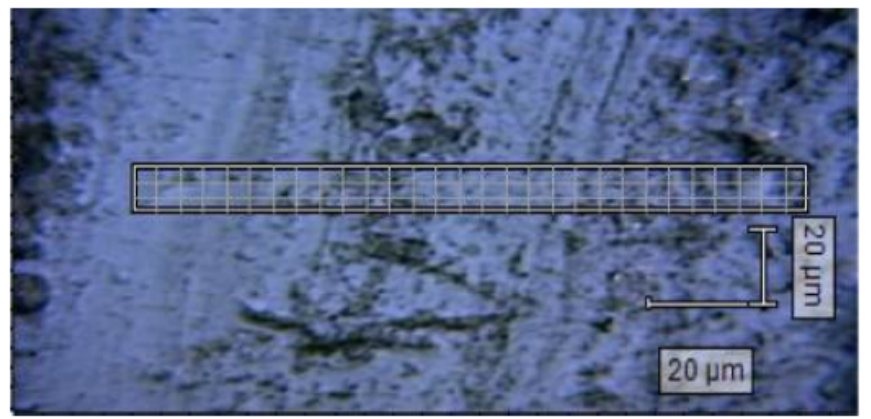

(a)

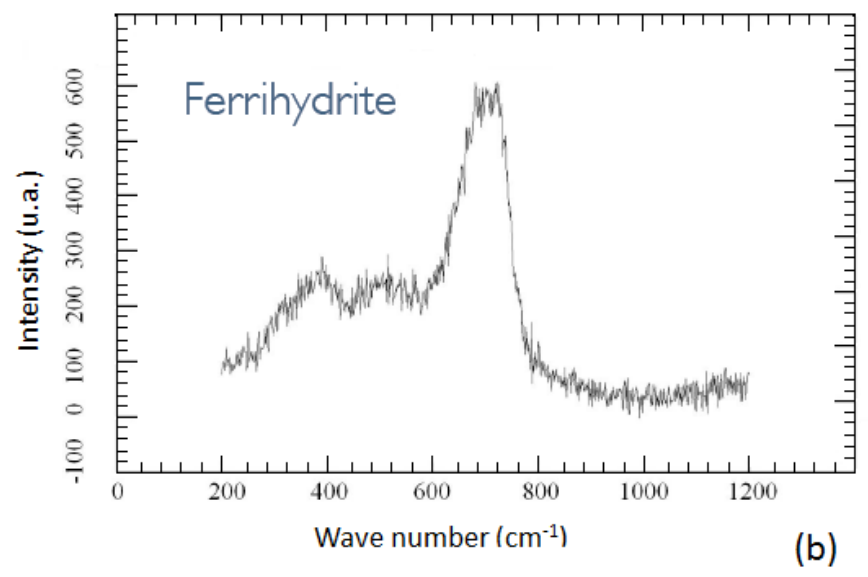

Figure 6: Raman microspectrometry on corrosion synthetized under imposed current. (a): Optical microscopic view of the analyzed zone, 120 points; (b): Typical Raman spectrum of ferrihydrite. 

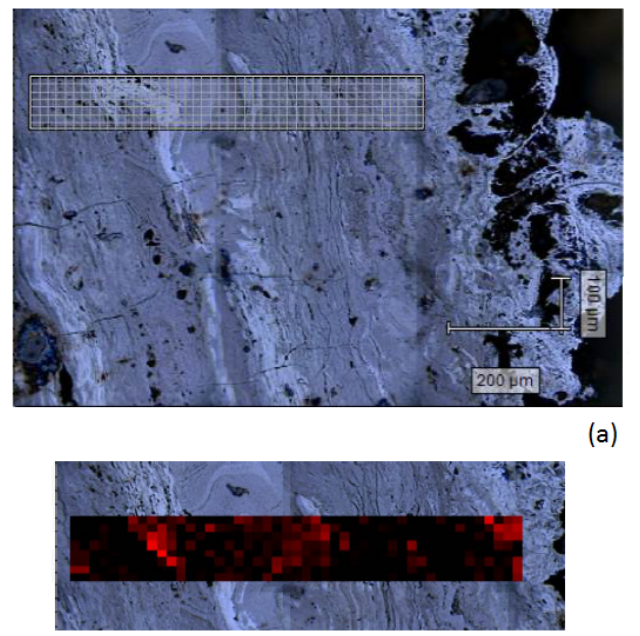

Maghemite

(d)

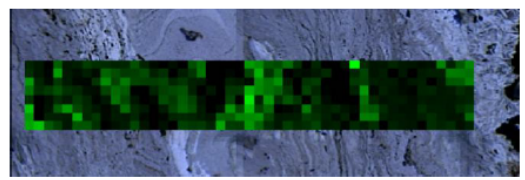

Ferrihydrite

(e)

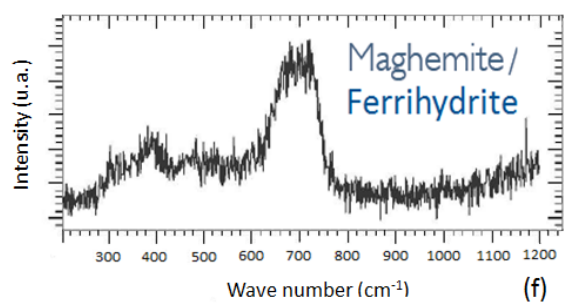

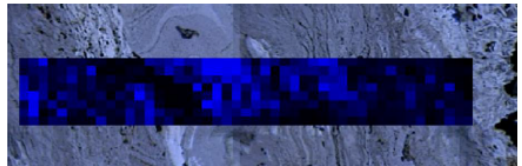

(b)

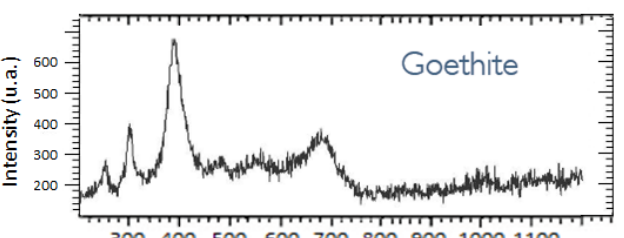

30040050060070080090010001100

Wave number $\left(\mathrm{cm}^{-1}\right)$

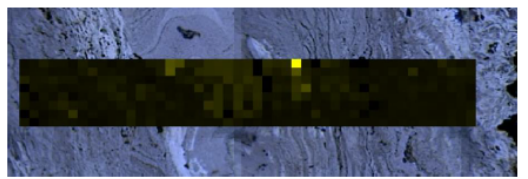

(g)

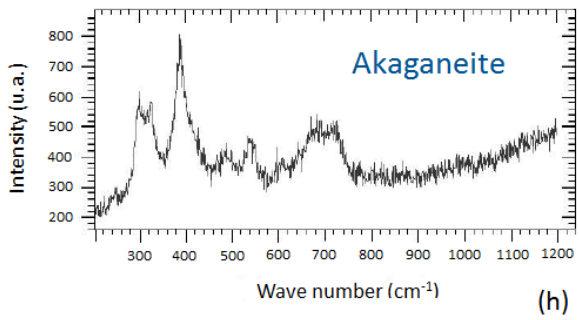

(h)

Figure 7: Raman microspectrometry on a 14 years-old rebar corroded in a saline environment. (a): Optical microscopic view of the analyzed zone, 376 points; (b,c): Phase repartition of goethite obtained with CorATmos software and typical spectrum; (d,e,g): CorATmos analysis on the clear marblings (magnetite/ferrihydrite and locally akaganeite); $(\mathrm{f}, \mathrm{h})$ : Typical Raman spectra of maghemite/ferrihydrite and akaganeite. 


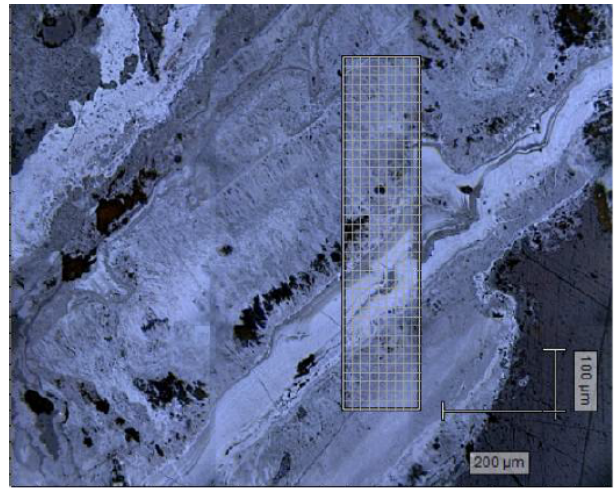

(a)

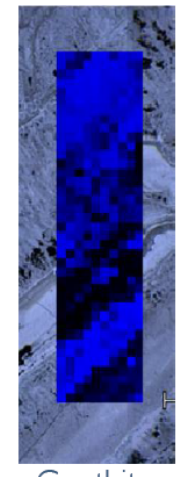

Goethite

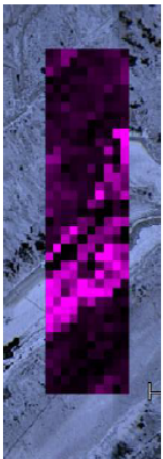

Magnetite

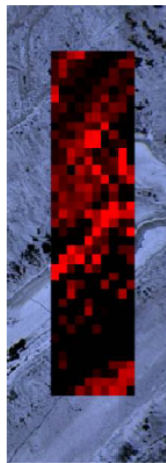

Maghemite

Magnetite/Maghemite
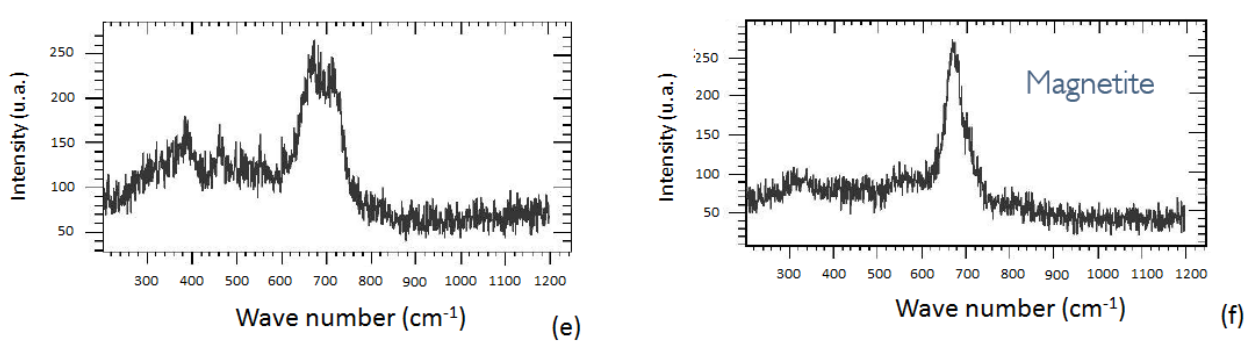

e)

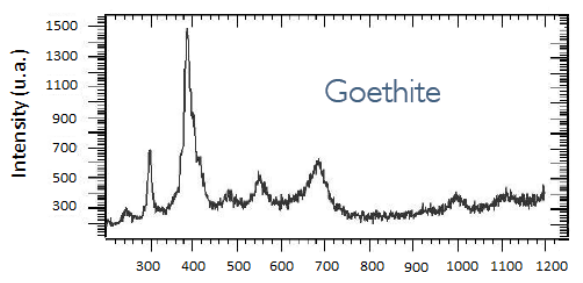

Wave number $\left(\mathrm{cm}^{-1}\right)$

(g)

Figure 8: Raman microspectrometry on a 25 years-old rebar corroded in a saline environment. (a): Optical microscopic view of the analyzed zone, 390 points; (b,c,d): Phase repartition of goethite, magnetite and maghemite obtained with CorATmos software; (e,f,g): Typical Raman spectra on the clear marblings (magnetite/maghemite) and the dark matrix (goethite). 


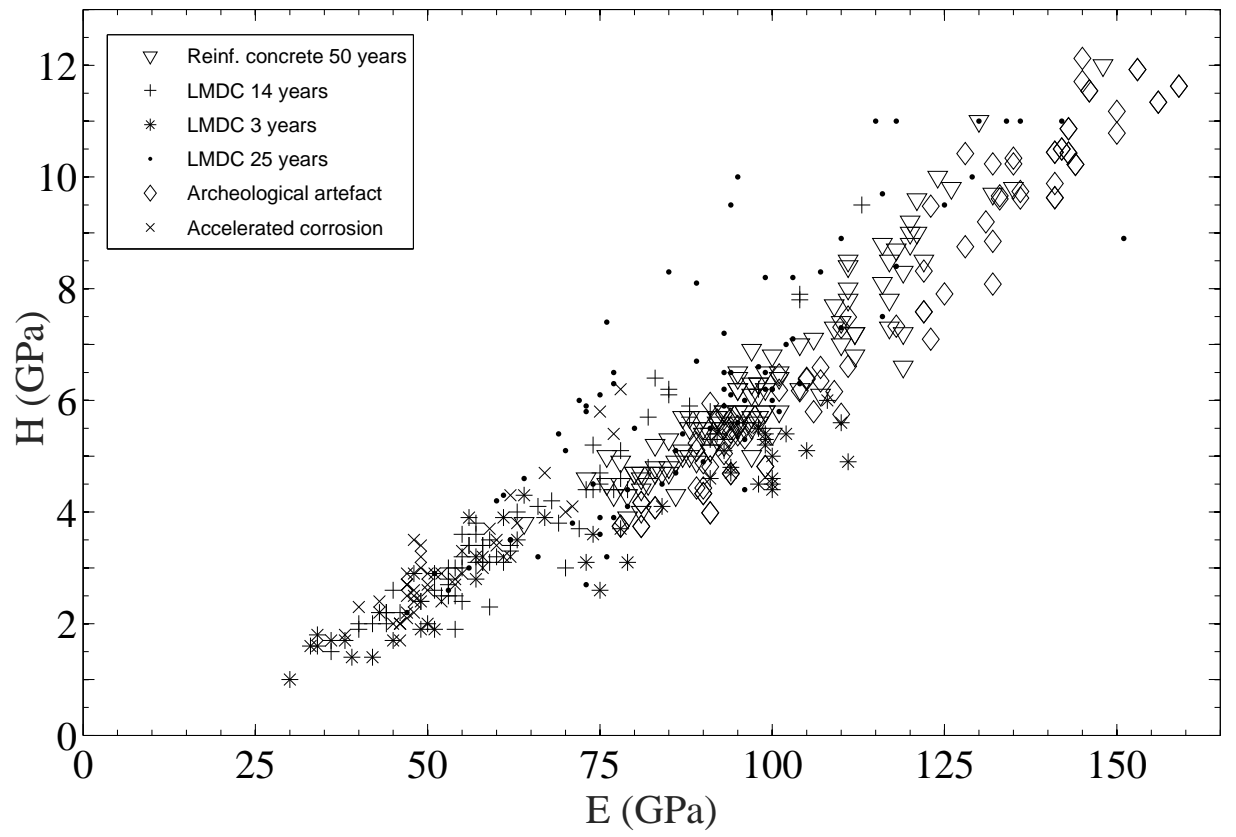

Figure 9: Hardness and elasticity modulus measured on the whole set of indentation points (448 points).
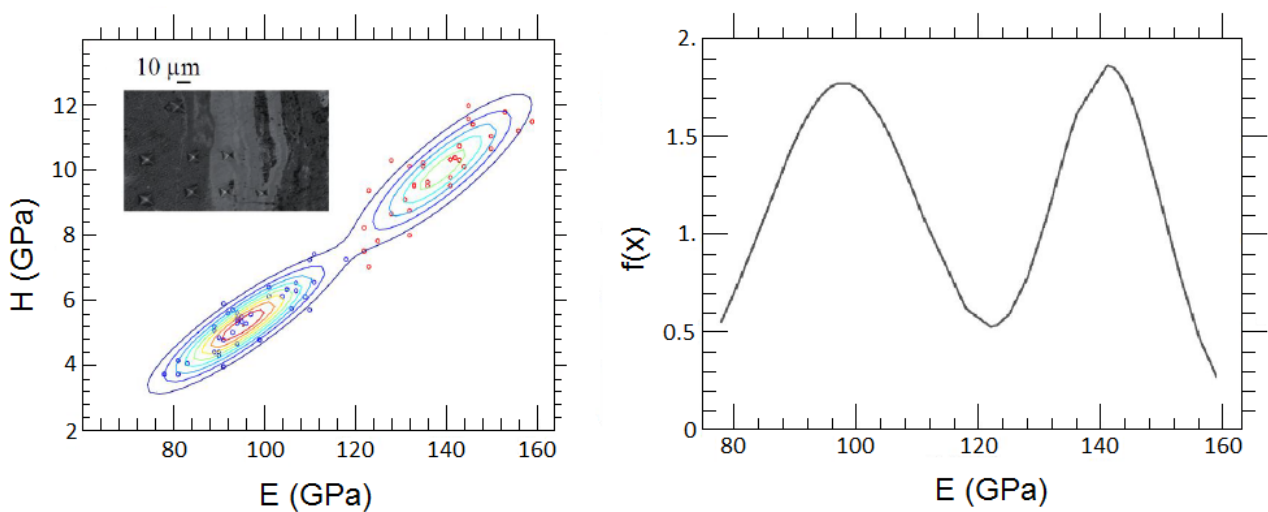

Figure 10: Exploitation of indentation tests by Gaussian Mixture Models. Indentation tests results and resulting Gaussian distribution for the ancient artefacts. 


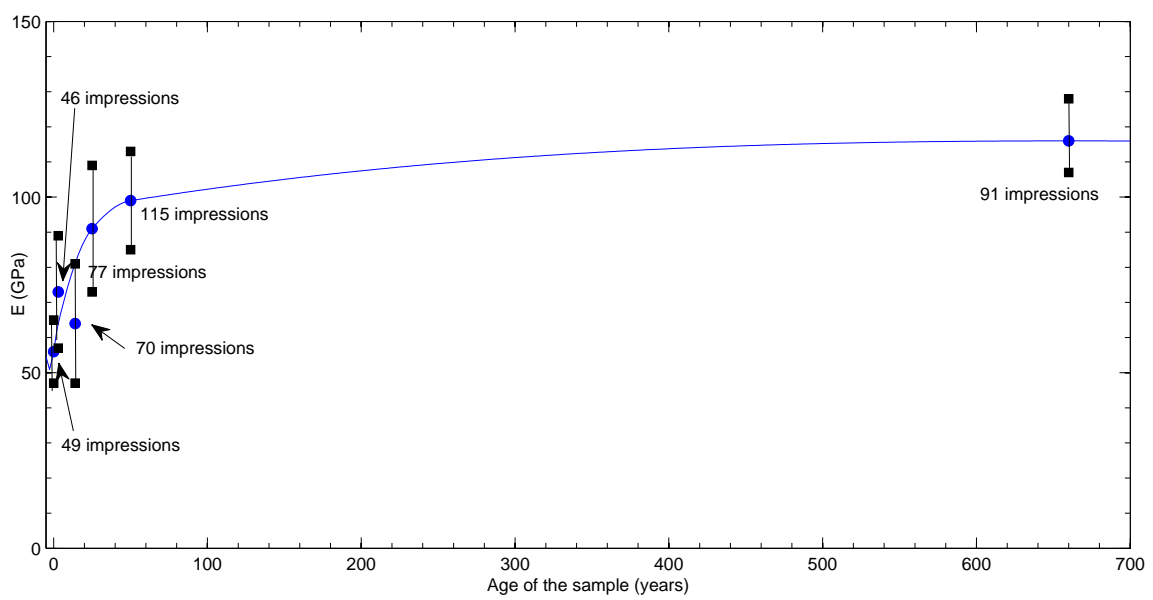

Figure 11: Variation of the average Young's modulus with the age of the corroded samples. 